Gut, 1982, 23, 137-139

\title{
Gastro-oesophageal candidiasis
}

\author{
B B SCOTT AND D JENKINS \\ From the Departments of Medicine and Pathology, Lincoln County Hospital, Lincoln
}

SUMMARY A prospective search for gastro-oesophageal candidiasis was made by histological examination of all the biopsies taken from 465 patients endoscoped consecutively during a 12 month period. The criterion for diagnosis was the demonstration of infiltration of tissue or ulcer slough by yeasts and hyphae. Nineteen cases of candidiasis were found giving an overall incidence of $4 \%$. There were 12 cases with oesophageal candidiasis, two with both oesophageal and gastric candidiasis, and five with gastric candidiasis. In none of the patients was candidiasis suspected before endoscopy. Symptoms referable to the candidiasis were uncommon and radiology was not helpful in diagnosis. There was associated local pathology (particularly peptic ulceration and carcinoma of the stomach or oesophagus) in all except two patients, which suggests that the candidiasis is usually secondary to mucosal damage. In the series, candidiasis was present in $27 \%$ of patients with oesophageal cancer, $20 \%$ of patients with gastric cancer, $16 \%$ of patients with benign gastric ulcers, and $15 \%$ of patients with oesophagitis.

Until recently gastro-oesophageal candidiasis was considered to be rare and to occur mainly in debilitated or immunosuppressed patients. However, in 1976 an endoscopic survey in New York ${ }^{1}$ discovered 27 cases among 370 consecutive endoscopies. These were all recognised by the presence of white plaques and direct smears and cultures were positive for candida as were serum agglutination tests. Tissue invasion, however, was apparently found only in three patients. A pathological study of 72 resected gastric ulcers in $1978^{2}$ found candidiasis - that is, yeasts and hyphae infiltrating tissue or ulcer slough-in $18 \%$ and these were associated with a high postoperative mortality of $38 \%$.

In view of these unexpected findings we undertook a prospective study during 1980 to determine the incidence and features of gastrooesophageal candidiasis in endoscoped patients.

\section{Methods}

A total of 465 patients undergoing upper gastrointestinal fibreoptic endoscopy during 1980 was included in the study. Histological sections from all endoscopic gastric and oesophageal biopsies were treated with diastase, stained with PAS, and examined for fungi. Usually four biopsies

Received for publication 27 July 1981 were taken from lesions in the oesophagus and six from lesions in the stomach.

The criterion for the diagnosis of candidiasis was the finding of infiltration by yeasts and hyphae of tissue or ulcer slough in histological sections of biopsies. Surface fungi were ignored. We do not consider that the demonstration of candida in smears and cultures is reliable evidence for candidiasis, as this organism is a common commensal and its presence does not imply a pathogenic role. ${ }^{3}$ Similarly, positive candida agglutination tests are not reliable, as they occur in control subjects. ${ }^{1}$ Consequently serology was not done, and culture of biopsies for candida was not done routinely.

\section{Results}

Nineteen patients were found to have candidiasis, giving an incidence at endoscopy of $4 \%$. Details of these patients are shown in Table 1. In none was candidiasis suspected before endoscopy, although one patient was seen to have oral thrush at the time of endoscopy. None was diabetic or had a haematological disorder or was taking a drug which might cause immunosuppression.

At endoscopy oesophageal white patches or plaques-that is, more discrete, raised patchessuggested the possibility of candidiasis in all except two of the patients with oesophageal candidiasis. However, white patches were also seen in 28 
Table 1 Details of patients with candidiasis

\begin{tabular}{|c|c|c|c|c|c|c|}
\hline No. & $\begin{array}{l}\text { Age } \\
(y r)\end{array}$ & Sex & $\begin{array}{l}\text { Oesophageal } \\
\text { white plaques }\end{array}$ & Associated local pathology & $\begin{array}{l}\text { Symptoms attributed } \\
\text { to candidiasis }\end{array}$ & $\begin{array}{l}\text { Barium } \\
\text { done }\end{array}$ \\
\hline \multicolumn{7}{|c|}{ Oesophageal candidiasis } \\
\hline $\begin{array}{l}1 \\
2 \\
3 \\
4\end{array}$ & $\begin{array}{l}65 \\
88 \\
75 \\
56\end{array}$ & $\begin{array}{l}\mathbf{M} \\
\mathbf{M} \\
\mathbf{M} \\
\mathbf{M}\end{array}$ & $\begin{array}{l}+ \\
- \\
\bar{t}\end{array}$ & $\begin{array}{l}\text { Oesophageal adenocarcinoma } \\
\text { Oesophageal adenocarcinoma } \\
\text { Oesophageal squamous cancer } \\
\text { Barrett's oesophagus }\end{array}$ & $\begin{array}{l}- \\
\overline{-} \\
\overline{\text { Epigastric pain, }} \\
\text { haematemesis }\end{array}$ & $\begin{array}{l}+ \\
+ \\
+ \\
-\end{array}$ \\
\hline $\begin{array}{r}5 \\
6 \\
7 \\
8 \\
9 \\
10 \\
11 \\
12\end{array}$ & $\begin{array}{l}71 \\
52 \\
76 \\
39 \\
79 \\
70 \\
67 \\
73\end{array}$ & $\begin{array}{l}\mathbf{F} \\
\mathbf{M} \\
\mathbf{F} \\
\mathbf{M} \\
\mathbf{F} \\
\mathbf{M} \\
\mathbf{F} \\
\mathbf{M}\end{array}$ & $\begin{array}{l}+ \\
\bar{t} \\
+ \\
- \\
\bar{t} \\
-\end{array}$ & $\begin{array}{l}\text { Achalasia } \\
\text { Hiatus hernia } \\
\text { Hiatus hernia } \\
\text { Gastric and duodenal ulcer } \\
\text { Duodenal ulcer } \\
\text { Duodenal ulcer } \\
\text { None (colonic cancer) } \\
\text { None (steroid inhaler) }\end{array}$ & $\begin{array}{l}\text { Haematemesis } \\
\text { Haematemesis } \\
\text { Retrosternal pain } \\
- \\
\overline{\text { Heartburn, vomiting }} \\
\text { Haematemesis }\end{array}$ & $\begin{array}{l}+ \\
- \\
- \\
+ \\
+ \\
+ \\
- \\
-\end{array}$ \\
\hline \multicolumn{7}{|c|}{ Oesophageal and gastric candidiasis } \\
\hline 13 & 83 & $\mathbf{M}$ & + & Gastric adenocarcinoma & $\begin{array}{l}\text { Epigastric } \\
\text { burning pain }\end{array}$ & + \\
\hline 14 & 80 & $\mathbf{F}$ & + & Antral adenocarcinoma & - & + \\
\hline \multicolumn{7}{|c|}{ Gastric candidiasis } \\
\hline $\begin{array}{l}15 \\
16 \\
17 \\
18 \\
19\end{array}$ & $\begin{array}{l}69 \\
59 \\
58 \\
55 \\
63\end{array}$ & $\begin{array}{l}\mathbf{F} \\
\mathbf{F} \\
\mathbf{F} \\
\mathbf{F}\end{array}$ & $\begin{array}{l}- \\
\overline{-} \\
-\end{array}$ & $\begin{array}{l}\text { Benign gastric ulcer } \\
\text { Benign gastric ulcer } \\
\text { Benign gastric ulcer } \\
\text { Benign gastric ulcer } \\
\text { Benign gastric ulcer }\end{array}$ & $\begin{array}{l}- \\
\overline{-} \\
\overline{-}\end{array}$ & $\begin{array}{l}- \\
\overline{-} \\
- \\
-\end{array}$ \\
\hline
\end{tabular}

patients without histological evidence of candidiasis according to our criterion and 10 of these also had white plaques. To determine the significance of white patches and plaques in those patients without evidence of candidiasis, histological features were compared in (1) eight of the patients with oesophagitis and no whiteness, (2) nine of the patients with white patches, and (3) nine of the patients with white plaques. Spongiosis, basal hyperplasia, polymorph infiltration, and clear swelling of epithelial cell cytoplasm were present considerably more frequently in biopsies from patients with whiteness than in those with oesophagitis but no whiteness. The same features were more marked in the patients with white plaques than in those with white patches. Pathology other than oesophagitis was not found in those patients with white patches or plaques and surface yeasts were seen only in two. Biopsy culture for candida was done in one patient with candidiasis and this was positive for Candida albicans. Associated local pathology was found in all except two patients, one of whom had colonic carcinoma and the other used a steroid inhaler for asthma. In view of the high incidence of associated local pathology it was difficult to decide whether symptoms were due to candidiasis or to the local pathology; in seven patients in whom symptoms could have been due to candidiasis there may have been underlying reflux oesophagitis and this alone may have been responsible for the symptoms. In nine patients a barium swallow was carried out but in none did it suggest candidiasis.

The incidence of candidiasis in relation to individual gastro-oesophageal pathology is shown in Table 2. Thirty per cent of patients with oesophageal carcinoma and $28 \%$ of patients with a protruberant gastric carcinoma had candidiasis. Neither of the patients with a malignant gastric ulcer had candidiasis compared with $16 \%$ of patients with a benign gastric ulcer.

Table 2 Incidence of candidiasis in relation to individual local pathology

\begin{tabular}{lccc}
\hline Local pathology & Total no. & \multicolumn{2}{c}{ With candidiasis } \\
& & (no.) & (\%) \\
\hline Oesophagitis & & & \\
$\quad$ White patches* & 40 & 12 & 30 \\
$\quad$ White plaques & 18 & 8 & 44 \\
$\quad$ No white patches or plaques & 52 & 2 & 4 \\
Oesophageal carcinoma & 5 & $2 \dagger$ & 40 \\
$\quad$ Adenocarcinoma & 6 & $1 \dagger$ & 16 \\
$\quad$ Squamous carcinoma & 4 & $1 \dagger$ & 25 \\
Achalasia & 32 & 5 & 16 \\
Benign gastric ulcer & 3 & 0 & \\
Gastric carcinoma & 7 & 2 & 28 \\
$\quad$ Ulcer & & & \\
Protruberant growth & & & \\
\hline
\end{tabular}

*With or without plaques.

†These patients are also included among those with oesophagitis.

\section{Discussion}

We have confirmed a high incidence of unsuspected gastro-oesophageal candidiasis among patients 
undergoing upper gastrointestinal fibreoptic endoscopy. Our incidence of $4 \%$ was less than the $8 \%$ found in New York, ${ }^{1}$ and this was possibly due to the stricter criterion adopted. All the patients with oesophageal white plaques in the New York study were considered to have candidiasis. In this study, white patches in the oesophagus of patients with oesophagitis were frequently found with or without evidence of candidiasis, and our results confirm the suggestion that this is simply a reflection of the severity of the oesophagitis. ${ }^{4}$ In the presence of white patches it is often difficult to identify plaques with confidence. In half of our patients with oesophageal candidiasis plaques were not found, and they were present in 10 patients without evidence of candidiasis. Had we used the presence of white plaques as a criterion our incidence of candidiasis would have risen to $6 \%$. As we took multiple, precisely located biopsies from white plaques in all patients with them and found candidiasis in only $44 \%$ we feel that white plaques are not a reliable indicator of candidiasis.

The incidence of candidiasis in benign gastric ulcers in this study $(16 \%)$ was very similar to the incidence found by Katzenstein and Maksem $^{2}$ $(18 \%)$ in their study of resected ulcers. These results suggest that the presence of candidiasis in a gastric ulcer should not raise the suspicion of malignancy.

The presence of associated local pathology in nearly all patients (which accords with the experience of Kodsi et al. ${ }^{1}$ ) suggests that the candidiasis is secondary to mucosal damage. However, it is possible that the candida has a secondary role in aggravating and perpetuating the underlying mucosal damage as suggested by Katzenstein and Maksem. ${ }^{2}$

In view of the high incidence of candidiasis in oesophageal carcinoma it would be sensible to give antifungal therapy routinely to such patients undergoing palliative intubation, as extension and systemic spread of the candidiasis might otherwise be precipitated.

\section{References}

1 Kodsi BE, Wickremesinghe PC, Kozinn PJ, Iswara K, Goldberg PK. Candida esophagitis-a prospective study of 27 cases. Gastroenterology 1976; 71:715-9.

2 Katzenstein AA, Maksem J. Candidal infection of gastric ulcers. Am J Clin Pathol 1979; 71:137-41.

3 Gorbach SL, Nahas L, Lerner PI. Studies of intestinal microflora I. Gastroenterology 1967; 53:845-55.

4 Thompson H. Pathology of reflux oesophagitis. In: Clinics in gastroenterology. London: Saunders, 1976; 5:143-53. 